\title{
A relação entre sintaxe e discurso no ensino de línguas estrangeiras
}

\author{
Carlos Felipe da Conceição Pinto (PINTO, Carlos Felipe da C.) \\ Doutorando na Universidade Estadual de Campinas - UNICAMP \\ Bolsista da Fundação de Amparo à Pesquisa do Estado de São Paulo \\ cfcpinto@gmail.com
}

\section{Resumo}

Os estudos em gramática funcional e gerativa vêm mostrando que a estrutura sintática da língua está estreitamente relacionada com a estrutura informacional da sentença. Nessa perspectiva, sentenças como "Se enojó Juan" e "Juan se enojó", do espanhol, embora apresentem o mesmo valor de verdade do ponto de vista semântico, não são utilizadas nos mesmos contextos discursivos, tendo-se em conta que apresentam estruturas informacionais diferentes. Este artigo tem a finalidade de discutir alguns aspectos da relação entre sintaxe e discurso no ensino de línguas estrangeiras considerando que, muitas vezes, línguas diferentes apresentam a mesma estrutura sintática com relação à ordem de palavras, mas os contextos em que cada ordem de palavra aparece são diferentes e os aprendizes tendem a transportar a estrutura informacional da língua materna para a língua estrangeira. $\mathrm{Na}$ primeira parte, são discutidas algumas noções pragmático-discursivas como foco-pressuposição, temarema, tópico-comentário, informação velha-informação nova, foco informativo-foco contrastivo. Na segunda parte do texto, são apresentados dados do português e do espanhol que mostram que, embora as línguas tenham em geral a mesma ordem de palavras, seus usos discursivos são diferentes e, se não forem trabalhados corretamente, podem gerar interferência no processo de aprendizagem/aquisição da língua estrangeira.

Palavras-chave: língua espanhola, ensino de línguas, sintaxe, estrutura funcional da sentença.

\begin{abstract}
Studies in functional and generative grammar have been showing that the syntactical structure of language is strictly related to the informational structure of sentences. From this perspective, sentences in Spanish like "Se enojó Juan" and "Juan se enojó", although presenting the same truth-value from the semantic point of view, are not used in the same discursive contexts, since they present different informational structures. This article aims to discuss aspects of the relation between syntax and discourse in teaching foreign languages, considering that, many times, different languages present the same syntactic structure concerning word order, but the contexts in which each order of words is used are different and that learners tend to transfer the informational structure of their first language to the foreign one. Firstly, pragmatic discourse notions, such as focus-presupposition, theme-rheme, topic-commentary, old information-new information, informative focus-contrastive focus are discussed. Data is then presented
\end{abstract}


on Portuguese and Spanish sentences, showing that, although the two languages have, in general, the same word order, their discursive uses are frequently different. If they are not taught in an appropriate manner, they may generate interference in the process of learning/acquiring a foreign language.

Keywords: Spanish, language teaching, syntax, functional structure of the sentence.

\section{Introdução}

Este trabalho tem a finalidade de propor uma discussão sobre a relação entre sintaxe e discurso ${ }^{1}$ no ensino de línguas estrangeiras. Há bastante tempo, os profissionais da Lingüística Aplicada vêm mostrando a inadequação de um enfoque meramente estrutural no ensino de línguas e destacam a importância de um enfoque comunicativo. No entanto, na tarefa de ensinar os alunos a se comunicarem, os profissionais têm se esquecido da relação entre estrutura sintática da língua e suas funções discursivas. Vasta bibliografia tem sido produzida sobre o assunto dentro do Gerativismo e do Funcionalismo com relação à produção de falantes nativos. No entanto, percebemos que os professores de língua estrangeira não trabalham esse tema em sala de aula. Dessa forma, pretendemos oferecer uma contribuição aos professores de línguas estrangeiras no que se refere a este quesito porque, muito embora algumas línguas possam apresentar uma estrutura semelhante com relação à ordem de palavras, sobretudo se são línguas de mesma família, tais estruturas podem ser utilizadas em contextos pragmático-discursivos bem diferentes, um ponto que deve ser de fundamental importância numa abordagem comunicativa do ensino de línguas.

O trabalho está organizado da seguinte maneira: na seção 2, tecemos alguns comentários sobre a estrutura funcional da sentença, sobre as noções de tema e rema e sobre algumas estratégias utilizadas em cada caso. Na seção 3, apresentamos uma discussão sobre a relação entre ordem de palavras e a focalização (que é o foco central deste trabalho) e alguns recursos utilizados por diferentes línguas para focalizar elementos no discurso. $\mathrm{Na}$ seção 4, apresentamos algumas noções pragmáticodiscursivas como tópico e foco, contudo a discussão é centrada nas noções de foco (informacional e contrastivo). Na seção 5, apresentamos um tipo de estratégia bastante recorrente nas línguas humanas para a focalização, que são as construções de clivagem. A discussão se detém no contraste entre as estratégias possíveis no português e no espanhol. Na seção 6, oferecemos uma discussão sobre a aplicação desses conceitos no ensino de línguas estrangeiras e concluímos o trabalho.

Embora a proposta se aplique ao ensino de línguas estrangeiras como um todo, os exemplos são oferecidos predominantemente com dados do contraste entre o português e o espanhol ${ }^{2}$.

\footnotetext{
${ }^{1}$ Discurso, neste trabalho, não é entendido na concepção da Análise do Discurso. Mas sim como o contexto pragmático-lingüístico no qual a sentença é emitida.

${ }^{2}$ Este trabalho foi apresentado originalmente como um mini-curso no I SIMPOSIO INTERNACIONAL DE LENGUA ESPAÑOLA, realizado no Instituto Cervantes de São Paulo nos dias 25 e 26 de abril de 2008.
} 


\section{A estrutura informacional da sentença}

Lyons (1982), ao fazer uma revisão de algumas escolas e movimentos modernos em lingüística, comenta que um dos principais interesses da Escola de Praga foi a perspectiva funcional da sentença. Dentro dessa visão, duas sentenças como as ilustradas em (1a) e (1b) abaixo podem ser consideradas versões da mesma sentença.

(1) a. Hoje de manhã ele levantou tarde.

b. Ele levantou tarde hoje de manhã. (LYONS, 1982, p. 168)

A diferença entre (1a) e (1b) se refere ao que o falante assume que é informação nova e informação conhecida no discurso. Gutiérrez Ordóñez (2000) comenta que a tendência nas línguas é que a informação conhecida preceda a informação nova. Então, em (1a), "hoje de manhã" poderia ser considerada a informação conhecida e "ele levantou tarde" a informação nova. O contrário acontece em (1b).

Hernanz e Brucart (1987) e Zubizarreta (1999), ao estudarem a ordem das palavras e os efeitos discursivos que determinada ordem pode causar, mostram que as línguas dispõem de uma ordem básica, que é estabelecida independentemente de tais efeitos discursivos, e uma ordem marcada, que refletirá esses efeitos discursivos. No caso do espanhol, Zubizarreta (1999) diz que o espanhol padrão (estándar, em suas palavras) requer posposição verbal do sujeito nas sentenças interrogativas parciais (interrogativas-wh) ${ }^{3}$ :
a. ¿Qué compró Juan?
(O que comprou Juan?)
b. *¿Qué Juan compró?
(*O que Juan comprou?)
(ZUBIZARRETA, 1999, p. 4217)

Assim, a ordem WhVS da interrogativa em (2a) é intrínseca à gramática ${ }^{4}$ do espanhol não tendo qualquer relação com a estrutura informacional da sentença, dada a agramaticalidade da sentença em (2b).

Gutiérrez Ordóñez (2000) diferencia as funções representativas das funções informativas. As funções representativas são funções objetivas e podem ser comparadas com cenários de uma dramatização, que contêm pessoas que desempenham um papel na cena. Por exemplo, o verbo "comer" exige uma cena em que haja um ser que tenha capacidade de comer e outro ser que tenha a propriedade de ser comido. Já as funções informativas são funções subjetivas e dependem daquilo que o falante assume como conhecido ou novo para o seu interlocutor no momento da enunciação. Voltando ao caso do verbo "comer", é objetivo, por exemplo, que "o menino" tem a capacidade de comer e "o bolo" tem a propriedade de ser comido. No entanto, é subjetivo assumir que "o menino comeu algo" e que "o bolo foi comida por alguém" (a diferença entre as duas frases depende do que o falante assume que o ouvinte sabe do acontecimento). Dessa forma, uma sentença deve conter três níveis funcionais diferentes: o sintático, o semântico e o informacional.

\footnotetext{
${ }^{3}$ Como comentado por Zubizarreta (1999), o espanhol do Caribe não requer a posposição do sujeito em interrogativas parciais. Vejam-se, a esse respeito, por exemplo, López Morales (1992) e Toribio (2000). Para uma comparação da ordem de palavras nas interrogativas do espanhol caribenho com as interrogativas do espanhol não caribenho, ver Ordóñez e Olarrea (2006).

${ }^{4}$ Gramática aqui é entendida como gramática internalizada.
} 
Por outro lado, Hernanz e Brucart (1987) dizem que, às vezes, se produz um desajuste entre a estrutura sintática, formada por um sujeito e um predicado, e a estrutura funcional, organizada em torno de um tema e de um rema. O tema é sobre o que trata a oração e o rema é o que se enuncia acerca desse tema. Observem-se os exemplos em (3) e (4) extraídos de Hernanz e Brucart (1987, p. 79-80):
a. Dalila traicionó a Sansón.
(Dalila traiu Sansão)
b. A Sansón lo traicionó Dalila.

(Sansão, o traiu Dalila)

\section{a. DALILA traicionó a Sansón. \\ b. A SANSÓN traicionó Dalila. ${ }^{5}$}

Nas duas orações em (3) e (4), os níveis sintático e semântico, como funções objetivas, são as mesmas: Dalila - sujeito agente; a Sansón - objeto paciente. O que vem a ser alterado é a estrutura funcional (nível informacional): em (3a) o tema é "Dalila" e o rema, "traicionó a Sansón"; já em (3b), o tema é "A Sansón" e o rema, "lo traicionó Dalila". Em (4a), o rema é "Dalila" e o tema é "traicionó a Sansón"; já em (4b), o rema é "A Sansón" e o tema é "traicionó Dalila".

Os exemplos (3b) e (4b) ainda mostram que a estrutura sintática nem sempre coincide na topicalização e na focalização, haja vista que o tema pode ser redobrado por um clítico na sentença, como em ( $3 b$ ), ao contrário do rema que não é redobrado por um clítico como ilustrado em (4b). ${ }^{6}$

Sendo assim, todas as línguas oferecem aos seus falantes estratégias sintáticodiscursivas que lhes permitem enfatizar elementos de seu interesse no discurso. As línguas dispõem de dois tipos de estratégias de ênfase bastante recorrentes: a topicalização, que põe em evidência elementos já conhecidos pelos falantes (as chamadas informações dadas, ou seja, o tema ou tópico) além de definir o assunto da conversa, como em (3), e a focalização, que põe em destaque os elementos que expressam informação nova (o foco) como ilustrado em (4).

\section{A ordem de palavras e a focalização nas línguas humanas}

Desde muito tempo, os estudos já vinham sinalizando que as línguas apresentavam diferenças em relação à ordenação das palavras e que existe um numeroso grupo de línguas que parece não impor restrições com relação à ordem de palavras. Considerando apenas constituintes como sujeito $(\mathrm{S})$, verbo $(\mathrm{V})$ e objeto $(\mathrm{O})$, é possível estabelecer seis tipos de línguas: SVO, SOV, VSO, VOS, OVS, OSV. Dentro dessas possibilidades, existem línguas que são mais flexíveis e línguas que são menos flexíveis. No entanto, não existe língua que seja tão rígida que não permita a menor variação na ordem e nem existe língua que seja tão flexível que não tenha uma ordem básica. Assim, em uma língua SVO fixo, como é o caso do inglês, não estará totalmente vetada uma construção OSV, que terá algum valor pragmático discursivo diferenciado

\footnotetext{
${ }^{5} \mathrm{O}$ maiúsculo indica que há uma entonação específica sobre os elementos.

${ }^{6}$ Sobre algumas diferenças sintáticas entre tema e rema (ou tópico e foco) ver Rizzi (1997). Sobre a duplicação de sintagma nominal por um clítico no espanhol, ver Correa (2006a), para uma análise discursiva, e Correa (2006b), para uma análise formal.
} 
da construção $\mathrm{SVO}^{7}$ Por outro lado, uma língua flexível como o walpiri, língua aborígine australiana, impõe uma única restrição sintática, que é a de que o verbo seja o segundo constituinte da sentença (cf. HERNANZ; BRUCART, 1987, p. 73-74).

Considerando a modalidade declarativa, a ordem básica pode ser definida pela maneira como os falantes respondem a uma pergunta como "O que aconteceu?", já que a resposta não estará dividida num par "tema-rema", sendo a resposta considerada toda como o rema (cf. GUTIÉRREZ ORDÓÑEZ, 2000, p. 23-27). ${ }^{8}$ Se o falante responde a essa pergunta com uma sentença como "O Pedro comeu o bolo", a ordem básica pode ser considerada SVO; se o falante responde com uma sentença como "Comeu o Pedro o bolo", essa língua pode ser considerada como uma língua VSO, e assim por diante.

Considerando as sentenças marcadas, divididas em um tema e um rema, como comentado na seção anterior, Lambrecht (2001) destaca as seguintes estratégias como recursos de focalização em diferentes línguas:

(5) Contexto: Seu joelho está doendo?
a. inglês
No, my foot hurts. / No, it's my foot that hurts.
$\mathrm{SV} /$ it-cleft

(Não, meu pé dói / Não, expl é meu pé que dói)

b. alemão Nein, mein Fuss tut weh.

SV

(Não, meu pé dói)

c. italiano No, mi fa male il PIEDE. / No, è il PIEDE che mi fa male VS / it-cleft

(Não, me dói o pé / Não, é o pé que me dói)

d. francês Non, c'est mon PIED qui me fait mal.

it-cleft

(Não, expl é meu pé que me dói)

(LAMBRECHT, 2001, p. 486)

(6) Contexto: Por que você está andando tão devagar?

a. inglês My foot hurts.

${ }^{7}$ Observar que existem línguas com ordem livre de palavras e línguas com ordem livre de constituintes. Hernanz e Brucart (1987, p. 103) ilustram essa diferença com exemplos de Lope de Vega (séc. XVII) e Gustavo Adolfo Bécquer (séc. XIX), como em (i) e (ii) respectivamente abaixo:

(i) "En una de fregar cayó caldera"

(Em uma de esfregar caiu caldeira - "caiu em uma caldeira de esfregar")

(ii) "Del salón en el ángulo oscuro, (Da sala no ângulo escuro, de su dueño tal vez olvidada, de seu dono talvez esquecida, silenciosa y cubierta de polvo, silenciosa e coberta de pó veíase el arpa" via-se a harpa)

O exemplo (i) mostra ordem livre de palavras; por outro lado, o exemplo em (ii) mostra ordem livre de constituintes. No caso de que núcleos e projeções máximas sejam coincidentes não se pode determinar se é ordem livre de palavras ou de constituintes.

${ }^{8}$ Hinterhölzl e Petrova (2010) indicam que, mesmo nas línguas V2, aquelas línguas em que o verbo aparece na segunda posição da frase precedido exclusivamente por um constituinte qualquer independentemente de sua função sintática, como as línguas germânicas modernas em geral, exceto o inglês, a ordem OVS, por exemplo, não pode ser usada para responder a uma pergunta como "O que aconteceu?" porque toda a resposta é uma informação nova e, nas língua V2, o primeiro constituinte deve ter o traço [+ informação conhecida]. Neste caso de toda a sentença representar uma informação nova, o sujeito, por restrições sintáticas da faculdade da linguagem, é quem ocupará a primeira posição derivando a ordem SVO. 
(Meu pé dói)

b. alemão Mein Fuss tut weh. / Mir tut ein Fuss weh.

$\mathrm{SV} / \mathrm{OVS}$

(Meu pé dói / A mim, dói um pé)

c. italiano Mi fa male un piede. / Ho un piede che mi fa male.

VS / have-cleft

(Me dói um pé / Tenho um pé que me dói)

d. francês J'ai mon PIED qui me fait mal.

have-cleft

(Eu tenho meu pé que me dói)

(LAMBRECHT, 2001, p. 487)

Nos exemplos em (5), nos quais o contexto é de foco contrastivo, são encontradas algumas possibilidades sintáticas; por exemplo: a) SV e clivagem para o inglês; b) SV para o alemão; c) VS e clivagem para o italiano; d) clivagem para o francês. Por outro lado, nos exemplos em (6), que representam um contexto de foco informativo, existem outras possibilidades sintáticas; por exemplo: a) SV para o inglês; b) SV e OVS para o alemão; c) VS e clivagem para o italiano; d) clivagem para o francês. As possibilidades de focalização variam a depender do contexto, se o foco é informativo ou contrastivo; assim, o francês utilizará uma it-cleft para foco contrastivo, como ilustrado em (5d), e uma have-cleft para ilustrar um foco informativo, como em (6d).

\section{Algumas noções pragmático-discursivas ${ }^{9}$}

Como foi visto na seção anterior, a estrutura das respostas depende do contexto em que as perguntas ocorrem. Dessa maneira, é relevante distinguir aqui as noções (dicotomias) discursivas de tópico-comentário e foco-pressuposição.

Seguindo Zubizarreta (1999, p. 4218), tópico (tema) pode ser definido como aquilo sobre o que a oração trata e comentário como o que se fala sobre esse tema ${ }^{10}$. Além disso, Zubizarreta (1999) diferencia o tema discursivo do tema oracional. Veja-se o exemplo (7) a seguir tomado de Zubizarreta (1999, p. 4218):

(7) O Sr. González é um cientista muito erudito, porém sua originalidade deixa muito a desejar. ${ }^{11}$

Uma sentença como (7) pode ter como tema discursivo as possibilidades em (8a) e (8b), porém só (8a) pode ser considerado tema oracional.
a. O Sr. González.
b. A habilidade científica do Sr. González.

\footnotetext{
${ }^{9}$ A esse respeito, ver também o trabalho de Lambrecht (1994).

${ }^{10}$ Ver também Rizzi (1997).

${ }^{11}$ Tradução nossa de: "El Sr. González es un científico muy erudito, pero su originalidad deja mucho que desear.".Em vez de "Tradução nossa de" usar "Texto original". Excluir aspas da citação, colocá-la em itálico e excluir ponto final dentro das aspas.
} 
O tema discursivo pode funcionar como tema de unidades mais amplas que a oração e pode ser abstrato. O tema oracional deve ser uma expressão contida na oração.

Por sua vez, Zubizarreta $(1998,1999)$ define a noção de foco a partir da noção de pressuposição. O foco é a parte não-pressuposta e a pressuposição é a informação compartilhada pelo falante e pelo ouvinte no momento em que se emite um discurso dado. Assim, no exemplo em (9):

O que aconteceu?

o falante e o ouvinte devem compartilhar a informação de que aconteceu algo (a pressuposição) e o foco será o elemento que satisfaz logicamente a pressuposição.

\section{O foco}

Com relação ao tipo semântico do foco, Zubizarreta $(1998,1999)$ propõe uma distinção entre foco informativo por um lado e foco contrastivo e enfático por outro. ${ }^{12}$

O foco informativo é o elemento que atribui um valor a uma variável através de uma estrutura assertiva como a ilustrada em (10), adaptada de Zubizarreta (1998):

(10) Há um $x$, tal que $x$ comeu o bolo.

$\mathrm{O} x$, tal que $x$ comeu o bolo $=$ João $^{13}$.

A estrutura assertiva em (10) representa o par pergunta-resposta do tipo de (11):

(11) A: Quem comeu o bolo?

B: Foi João que comeu.

No outro lado, o foco contrastivo vai negar uma asserção prévia e faz uma nova asserção; o foco enfático vai confirmar uma asserção prévia. Zubizarreta $(1998,1999)$ considera que o foco contrastivo e o foco enfático são estruturalmente idênticos. $\mathrm{O}$ exemplo (12a) ilustra um caso de foco contrastivo e o exemplo (12b) um caso de foco enfático.

(12) a. FALANTE A: Você quer este livro?

FALANTE B: Não, quero O OUTRO.

b. FALANTE A: Você quer este livro?

FALANTE B: Sim, é ESSE MESMO que eu quero.

Zubizarreta $(1998,1999)$ ressalta que, em muitas línguas, a proeminência prosódica desempenha um papel fundamental na identificação do foco. Dessa forma, o acento tonal se associa à sílaba de maior proeminência dentro da palavra e, dentro do grupo melódico, a palavra de maior proeminência receberá o acento nuclear. Zubizarreta $(1998,1999)$ distingue dois tipos de acento nucleares: o acento nuclear

\footnotetext{
${ }^{12}$ Para outra definição de foco contrastivo e informativo, ver É Kiss (1998).

${ }^{13}$ Para uma introdução à semântica formal, ver Pires de Oliveira (2001).
} 
neutro e o acento nuclear enfático ou contrastivo; e mostra que, em espanhol ${ }^{14}$ (assim como em algumas outras línguas, conforme mostram outros estudos), o acento nuclear é colocado na palavra ou constituinte mais encaixado do grupo melódico.

(13) El gato se comió un ratón. ${ }^{15}$

(O gato comeu um rato) (ZUBIZARRETA, 1999, p. 4229)

Zubizarreta (1998, p. 19, 124) define formalmente essa regra fonológica como em (14):

(14) C-NSR: dadas duas categorias irmãs $\mathrm{C}_{1}$ e $\mathrm{C}_{2}$, a que estiver mais baixa na ordenação de c-comando assimétrico é a mais proeminente. ${ }^{16}$

Neste tipo de língua, no entanto, se o acento for colocado em outra posição que não a última palavra ou constituinte do grupo melódico, haverá uma interpretação enfática ou contrastiva:

\section{EL GATO comió un ratón. ${ }^{17}$ \\ (O GATO comeu um rato) (ZUBIZARRETA, 1999, p. 4229)}

A sentença em (15) é impossível, em espanhol, como uma resposta à pergunta "Quién se comió un ratón?", tendo em vista que, nesta língua, o foco informativo só pode ser identificado pelo acento neutro, como definido em (14). Como o acento contrastivo ou enfático pode ser colocado em qualquer posição, a estrutura do exemplo em (15) é possível como um exemplo de foco contrastivo ou enfático, como se pode perceber pelos exemplos seguintes em (16):

(16) A: ¿Quién va a ir al cine? ¿Pepe o Juanito?

(quem vai ao cinema? Pepe ou Juanito?)

B: JUANITO va a ir al cine, y no Pepe.

(JUANITO vai ao cinema, e não Pepe.)

Assim, como o espanhol requer que o acento neutro, que identifica o foco informativo, esteja numa posição mais encaixada, conforme as regras fonológicas propostas por Zubizarreta (1998), a prosódia desencadeará alterações sintáticas com a finalidade de satisfazer tal requerimento quando for necessário responder a uma pergunta como "¿Quién comió el pastel?", tendo em vista que a ordem neutra (não marcada) em espanhol é SVO.

\footnotetext{
${ }^{14}$ Essa propriedade, embora não seja universal, conforme detalhado em Zubizarreta $(1998,1999)$, também acontece em outras línguas, como é o caso do italiano. No caso do português brasileiro ou do inglês, como se verá mais adiante, esta propriedade não se aplica.

${ }^{15}$ Devido às normas editoriais, o sublinhado do texto original foi substituído por itálico para indicar o acento nuclear neutro.

${ }^{16}$ Tradução de: C-NSR: Given to sister categories Ci and Cj, the one lower in the asymmetric c-command ordering is more prominent.

${ }^{17} \mathrm{O}$ maiúsculo indica que o constituinte recebeu acento contrastivo ou enfático.
} 


\section{A clivagem ${ }^{18}$}

A clivagem é um recurso de focalização, no qual o elemento focalizado é ensanduichado a partir de uma estrutura sintática específica contendo simplificadamente uma cópula focalizadora (SER) e pronome relativo ou conjunção. A seguir, apresentamos a tipologia da clivagem em português ${ }^{19}$ e em espanhol ${ }^{20}$ :

(17) Construções de clivagem no português

a. Foi O LIVRO que a Maria comprou.

b. O LIVRO foi que a Maria comprou.

c. O LIVRO que a Maria comprou.

d. O que a Maria comprou foi O LIVRO.

e. O LIVRO foi o que a Maria comprou.

f. Foi O LIVRO o que a Maria comprou.

g. A Maria comprou foi O LIVRO.

h A: Você comprou o caderno?

B: Não... Foi o livro

\author{
Clivada Básica (CL) \\ Clivada Invertida (CI) \\ Clivada sem cópula (CSC) \\ Pseudo-clivada Básica (PC) ${ }^{21}$ \\ Pseudo-clivada Invertida (PCI) \\ Pseudo-clivada Extraposta (PCE) \\ Pseudo-clivada Reduzida (PCR) \\ Pseudo-clivada Truncada (PCT)
}

(18) Construções de clivagem no espanhol

a. Es DE MARÍA que todos hablan.

b. DE MARÍA es que todos hablan.

c. De MARÍA que todos hablan.

d. De quien todos hablan es DE MARÍA

e. DE MARÍA es de quien todos hablan.

f. Es DE MARÍA de quien todos hablan.

g. Todos hablan es DE MARÍA.

h A: ¿De quien hablan todos?

B: Es de María

Clivada Básica (CL)
Clivada Invertida (CI)
Clivada sem cópula (CSC)
Pseudo-clivada Básica (PC)
Pseudo-clivada Invertida (PCI)
Pseudo-clivada Extraposta (PCE)
Pseudo-clivada Reduzida (PCR)
Pseudo-clivada Truncada (PCT)

Conforme muitos estudos vêm mostrando, a distribuição das construções de clivagem no espanhol não é uniforme. Moreno Cabrera (1999) e Di Tullio (2005) dizem que (18a) e (18b) são exclusivas do espanhol americano. Di Tullio (2005) destaca que: "ambos, o espanhol europeu e o espanhol americano, possuem as pseudo-clivadas. Até o momento, só o espanhol americano tem as reais clivadas, que são recusadas pelos

\footnotetext{
${ }^{18}$ Adotamos, como em Pinto (2008), a definição de clivagem proposta por Modesto (2001, p. 21): "as construções clivadas são sentenças especificacionais em que um movimento A-barra dispara leituras características de contraste, exclusividade e exaustividade". Para um estudo da clivagem, ver Kato et al. (1996), Moreno Cabrera (1999), Modesto (2001) e Pinto (2008).

${ }^{19} \mathrm{~A}$ discussão se deterá nas opções permitidas em Português Brasileiro tendo em vista que o público alvo são falantes brasileiros que aprendem uma língua estrangeira, em especial o espanhol. A exceção da construção ilustrada em (17c), todas as demais construções existem tanto no português brasileiro como no português europeu. Contudo, há uma diferença discursiva entre $\mathrm{PE}$ e PB no tocante às construções ilustradas em (17a) e (17f): somente o PB pode utilizar essas construções para indicar um foco informacional embora ambas as variedades possam utilizá-la para indicar um foco contrastivo.

${ }^{20}$ Utilizamos o termo "espanhol" cientes de que se trata de um conjunto de variedades lingüísticas e não como um bloco homogêneo mesmo quando não for especificado o termo "espanhol de [...]". Sobre esse tema, ver Fontanella de Weinberg (1993), Fanjul (2004) e Pinto (2009).

${ }^{21}$ Para uma distinção entre clivadas e pseudo-clivadas, ver Modesto (2001) entre outros.
} 
gramáticos normativos". ${ }^{22}$ Com relação a (17g), os autores comentam que é específica do espanhol do Caribe.

Pinto (2008) faz uma análise das estratégias de focalização em quatro variedades do espanhol (México, Argentina, Espanha e Cuba) e mostra que: a) as verdadeiras clivadas, como ilustrado em (18a) e (18b) são possíveis na Argentina e em Cuba; b) não registra casos de PCR, como ilustrado em (17g), no corpus analisado; c) (17c) é possível no México e na Espanha.

Em termos discursivos, Pinto (2008) mostra que as únicas construções de clivagem que podem ser utilizadas para foco informativo no espanhol são as pseudoclivadas básicas e as pseudo-clivadas truncadas, construções em que o elemento focalizado aparece na posição mais encaixada. As demais construções, incluindo as PC e a PCT, são utilizadas para foco contrastivo. ${ }^{23}$

\section{Contrastes nos usos discursivos da clivagem em português e espanhol}

Como pôde ser visto pelos exemplos acima, o português brasileiro tem mais opções de clivagem que o espanhol em geral. Assim, os contextos discursivos em que cada construção de clivagem poderá aparecer em português podem ser mais amplos que em espanhol. ${ }^{24}$ Considerando-se um contexto de foco informativo, ${ }^{25}$ o PB e o espanhol utilizam estratégias diferentes para a resposta a uma pergunta como "quem telefonou?" 26 O PB pode utilizar as estratégias ilustradas em (19) e o espanhol as estratégias ilustradas em (20).

(19) a. Foi o João quem ligou.

b. Foi o João que ligou.

c. Quem ligou foi o João.

d. O João ligou.

e. *Ligou o João.
a. \#Fue Juan quien Ilamó. $^{27}$
b. \#Fue Juan que llamó.
c. Quien Ilamó fue Juan.
d. \#Juan llamó.
e. Llamó Juan.

\footnotetext{
${ }^{22}$ Texto original: Both European Spanish and American Spanish possess pseudoclefts, yet only American Spanish has real clefts, which are unacceptable for normative grammars.

${ }^{23}$ Camacho (2006) diz que é possível usar uma PCR, como (18g) para foco informativo. Veja-se que Pinto (2008) não registra esse tipo de construção no corpus analisado. Contudo, como a PCR é uma construção derivada da PC, como propõe Toribio (2002), ela mantém o elemento focalizado na posição mais encaixada, posição compatível com a focalização informacional.

${ }^{24}$ Para um estudo comparativo da clivagem em línguas românicas, ver Ribeiro (2006) e Pinto e Ribeiro (2006).

${ }^{25}$ Como dito acima, qualquer construção de clivagem pode ser usada, em espanhol, para representar um foco contrastivo.

${ }^{26}$ Como a ordem básica do espanhol é SVO, segundo Hernanz e Brucart (1987), menos problemáticas para os brasileiros são as estratégias de focalização que incidem sobre o objeto, já que, naturalmente, este elemento está na posição mais baixa e não requer nenhum movimento prosódico para satisfação do requisito fonológico.

${ }^{27} \mathrm{O}$ símbolo \# indica que a construção é gramatical, contudo inadequada para o contexto discurso.
} 
O contraste entre (19) e (20) não se refere a problemas estruturais (salvo no caso de (19e), que, de fato, é impossível em PB): todas as construções existem nas duas línguas. O problema é pragmático-discursivo: o contexto em que cada estrutura é possível nas duas línguas é substancialmente diferente. O PB permite que o foco informativo esteja em outra posição diferente da mais encaixada ${ }^{28}$, e o espanhol, ao contrário, exige que o foco informativo esteja na posição mais baixa. Se este elemento, na ordem não-marcada, naturalmente estiver numa posição alta, a sintaxe terá que fazer algo para o colocar em uma posição mais baixa ${ }^{29}$ para que possa ser interpretado corretamente como foco informativo. ${ }^{30}$

Belletti (2005) faz um estudo comparativo da produção de falantes nativos de italiano (uma língua de sujeito nulo, assim como o espanhol geral ${ }^{31}$ ) e de falantes de italiano como L2 cuja L1 é o francês (uma língua que não apresenta a propriedade do sujeito nulo). ${ }^{32}$ A autora mostra que, enquanto os falantes nativos de italiano produzem sempre a inversão VS para focalizar o sujeito, ${ }^{33}$ os falantes de francês, aprendizes de italiano, tendem a produzir uma clivada básica, o que mostra que há uma transferência da L1 para a L2. ${ }^{34}$

\section{Algumas observações e possíveis soluções}

É possível esperar que o que foi registrado em Belletti (2005) também aconteça no caso de falantes de PB L1 que aprendem espanhol L2. Isso foi o que observamos quando ministramos um curso sobre ordem de palavras no espanhol para professores brasileiros: diante da pergunta “¿quién llegó?” (e lhes foi dito que a pessoa que havia chegado era Juan), todos responderam "Juan llegó". Embora "Juan llegó" seja uma forma possível em espanhol, ou seja, gramatical, não foi utilizada no contexto adequado. Qualquer falante nativo de espanhol diria "Llegó Juan" já que a pergunta incide sobre o sujeito. ${ }^{35}$

\footnotetext{
${ }^{28}$ Sobre a focalização em português, ver Fernandes (2007).

${ }^{29}$ Zubizarreta (1998), como visto acima, chama esta operação de p-movement (prosodically motived movement - movimento motivado prosodicamente).

${ }^{30}$ Para uma análise da inversão VS como recurso de focalização diferente da análise proposta por Zubizarreta (1998), ver (1999, 2003, 2004, 2005) por exemplo.

${ }^{31}$ Observar que o espanhol do Caribe não tem mais essa propriedade de sujeito nulo (cf. TORIBIO, 2000, 2002).

${ }^{32}$ Observe-se que o caso é bem parecido com o contraste PB X espanhol geral.

${ }^{33}$ Como os estudos vêm mostrando (na linha de pesquisa de BELLETTI, 1999, 2003, 2004, 2005, que é diferente do posicionamento de ZUBIZARRETA, 1998, 1999), existem duas posições para o reconhecimento do foco, seja contrastivo ou informativo: a periferia interna e a periferia esquerda da sentença. As línguas podem escolher entre as duas possibilidades. Há línguas, como o italiano, que escolhem a periferia interna para foco informativo e a periferia esquerda para foco contrastivo; há línguas, como o siciliano, que realizam ambos os focos na periferia esquerda; há línguas, como o espanhol, que restringem o foco informativo na periferia interna e realizam o foco contrastivo na periferia esquerda; há línguas que realizam ambos os focos na periferia interna etc.

${ }^{34}$ Para uma discussão gerativista sobre a influência da L1 no processo de aquisição de L2, ver o primeiro capítulo de Correa (2007) e Pinto e Cavalcante (2008).

${ }^{35} \mathrm{E}$ isso não está relacionado ao tipo semântico do verbo "llegar", um verbo inacusativo. Um verbo de sujeito agentivo, como "trabajar", ou um verbo bivalente, como "comer", apresentarão a mesma característica de inversão VS neste contexto.
} 
Os professores de línguas estrangeiras devem ter em conta, no processo de ensino-aprendizagem da língua, que existe uma relação muito forte entre forma e significado (e aqui, indo mais além da dicotomia saussureana entre significado e singificante). Falando em termos de sintaxe, os professores devem averiguar se as mesmas formas estão disponíveis nas duas línguas (a materna e a estrangeira) e se todas as formas são usadas da mesma maneira nas duas línguas caso a primeira pergunta tenha resposta positiva. Como Hernanz e Brucart (1987) destacam, "Juan se enojo" e "Se enojo Juan" deixam de ser meras variantes da mesma sentença a partir do momento em que os estudos sobre a estrutura funcional da sentença entrem no cenário da investigação lingüística. Mais além disso: são sentenças que, embora sintática e semanticamente tenham o mesmo estatuto, funcionalmente não o têm.

Falando em comunicação e possibilidades da Gramática Universal, o caso que foi apresentado neste trabalho pode gerar ruído na comunicação tendo em vista que as formas naturalmente utilizadas pelos brasileiros para expressar um foco informativo sobre o sujeito (por exemplo, as construções de clivagem e a focalização in-situ, com ordem sujeito-verbo) não correspondem a respostas naturais para o mesmo contexto em espanhol.

Dessa maneira, um maior estudo da sintaxe e de sua relação com o contexto discursivo em que as construções sintáticas são empregadas pode ajudar muito aos aprendizes a não transferirem estruturas de sua língua materna para a língua estrangeira.

\section{Referências}

BELLETTI, Adriana. Inversion as focalization and related questions. CatWPL, v. 7, p. 9-45, 1999.

. Extended doubling and the VP periphery. University of Siena, ms., 2003.

Aspects of the low IP area. In: RIZZI, Luigi. (Org.). The structure of IP and $\overline{C P}$ : the cartography of syntactic structure. v. 2. Oxford: Oxford University Press, 2004. p. 16-51.

Answering with a "cleft": the role of the null subject parameter and the VP periphery. In: BRUGE, Laura; GIUSTI, Giuliana; MUNARO, Nicola; SCHWEIKERT, Walter; TURANO, Giuseppina. (Orgs.). Proceedings of the Thirtieth "Incontro di Grammatica Generativa”. Cafoscarina, Venezia, 2005. p. 63-82.

CAMACHO, José. In situ focus in Caribbean Spanish: towards a unified account of focus. In: SAGARRA, Nuria; TORIBIO, Almeida Jacqueline. (Orgs). Selected Proceedings of the 9th Hispanic Linguistics Symposium. Somerville: Cascadilla Press, 2006. p. 13-23.

CORREA, Paulo Antônio P. ¿Por qué SSNN se duplican obligatoriamente? In: BARROS, Luizete G.; COSTA, Maria José; VIEIRA, Vera R. (Orgs.). Hispanismo 2004. v. I. Florianópolis: ABH, 2006a. p. 429-440. 
Argumentos x núcleos focales: el estatus de los clíticos que duplican SSNN en español, D.E.L.T.A., v. 22, n. 2, p. 227-247, 2006 b.

A expressão da mudança de estado na interlíngua de aprendizes brasileiros de espanhol, 2007. Tese (Doutorado em Lingüística) - Universidade Federal do Rio de Janeiro, 2007.

DI TULLIO, Ángela. Clefting in spoken discourse. In: Encylopedia of language of linguistics. 2nd ed. Oxford: Oxford University Press, 2005.

É. KISS, Katalin. Identificational focus versus information focus. Language, v. 74, p. 245-273, 1998.

FANJUL, Adrián Pablo. Português Brasileiro, Espanhol de... onde? Analogias incertas, Letras \& Letras, v. 20, p. 165-183, 2004.

FERNANDES, Flaviane Romaine. Ordem, focalização e preenchimento em português: sintaxe e prosódia. 2007. Tese (Doutorado em Lingüística) - Universidade Estadual de Campinas, 2007.

FONTANELLA DE WEINBERG, Maria B. El español de América. 2. ed. Madrid: Mapfre, 1993.

GUTIÉRREZ ORDÓÑEZ, Salvador. Temas, remas, focos, tópicos y comentarios. 2. ed. Madrid: Arco/Libro, 2000.

HERNANZ, Maria Lluïsa; BRUCART, José Maria. La sintaxis. Princípios teóricos. La oración simple. v. 1. Barcelona: Crítica, 1987.

HINTERHÖLZL, Roland; PETROVA, Svetlana. From V1 to V2 in West Germanic. Língua, v. 120, issue 2, p. 315-328, 2010.

KATO, Mary Aizawa et alii. Construções-Q na gramática do português brasileiro falado: perguntas, clivadas e relativas. In: $\mathrm{KOCH}$, Ingedore G. V. (Org.). Gramática do português falado: desenvolvimentos. v. 6. Campinas: Editora da UNICAMP, 1996. p. 303-370.

LAMBRECHT, Knud. Information structure and sentence form. Topic, focus, and the mental representations of discourse referents. Cambridge Studies in Linguistics 71. Cambridge: Cambridge University Press, 1994.

A framework for the analysis of cleft constructions. Linguistics, v. 39, n. 3, p. 463-516, 2001.

LÓPEZ MORALES, Humberto. El español del Caribe. Madrid: Mapfre, 1992.

LYONS, John. Lingua(gem) e lingüística. uma introdução. Rio de Janeiro: Zahar Editores, 1982. 
MODESTO, Marcello. As construções clivadas no português do Brasil: relações entre interpretação focal, movimento sintático e prosódia. São Paulo: Humanitas, 2001.

MORENO CABRERA, Juan Carlos. Las funciones informativas: las perífrasis de relativo y otras construcciones perifrásticas. In: BOSQUE, Ignacio; DEMONTE, Violeta. (Orgs.). Gramática descriptiva de la lengua española. v. 3. Madri: Espasa Calpe, 1999. p. 4245-4302.

ORDÓÑEZ, Francisco; OLARREA, Antxon. Microvariation in Caribbean/non Caribbean Spanish interrogatives. Probus, v. 18, p. 59-96, 2006.

PINTO, Carlos Felipe da Conceição. Uma análise das construções de clivagem e outras construções focalizadoras no espanhol atual. 2008. Dissertação (Mestrado em Letras) Universidade Federal da Bahia, 2008.

. Los criterios sintácticos en la división dialectal del español. In: PINTO, Carlos Felipe; IRALA, Valesca Brasil. (Orgs.). Um dossiê de estudos lingüísticos hispânicos. São Paulo: Casa do Novo Autor, 2009.

; CAVALCATE, Rerisson. Algumas reflexões sobre GU, interlínguas e outros. In: Actas do V Simpósio Internacional de Didáctica para Extranjeros "José Carlos Lisboa”. Rio de Janeiro, Instituto Cervantes, 2008, no prelo.

PINTO, Carlos Felipe da Conceição; RIBEIRO, Ilza. Um estudo sintático-discursivo da clivagem em línguas românicas. In: Encontro Nacional de Língua Falada e Escrita, V. Maceió: UFAL, 2006.

PIRES DE OLIVEIRA, Roberta. Semântica formal: uma breve introdução. Campinas: Mercado das Letras, 2001.

RIBEIRO, Ilza. Clivagem e discurso. Diferentes estratégias em diferentes línguas. ms, 2006.

RIZZI, Luigi. The fine structure of the left periphery. In: HAEGEMAN, Liliane. (Org.). Elements of grammar. Kluwer: Dordrecht, 1997. p. 281-337.

TORIBIO, Almeida Jacqueline. Setting parametric limits on dialectal variation in Spanish, Língua, v. 10, p. 315-341, 2000.

Focus on clefts in Dominican Spanish. In: LEE, James; GEESLIN, Kimberly; CLEMENTS, J. Clancy. (Orgs.). Structure, meaning, and acquisition in Spanish. Somerville, MA: Cascadilla Press, 2002. p. 130-146.

ZUBIZARRETA, Maria Luisa. Prosody, focus, and word order. Linguistic Inquiry Monograph 33. Cambridge, Mass: The MIT Press, 1998.

Las funciones informativas: tema y foco. In: BOSQUE, Ignacio; DEMONTE, Violeta. (Orgs.). Gramática descriptiva de la lengua española. v. 3. Madri: Espasa Calpe, 1999. p. 4215-4244. 